\title{
What is the Benefit of Electronic Commerce Product Marketing for Doll Craft Products?
}

\author{
Agus Nursikuwagus ${ }^{1}$, and D Cahyadi ${ }^{2}$ \\ \{agusnursikuwagus@email.unikom.ac.id ${ }^{1}$, dcahyadi@mahasiswa.email.unikom.ac.id $^{2}$ \} \\ Departemen Sistem Informasi, Universitas Komputer Indonesia, Indonesia ${ }^{1}$ \\ Fakultas Teknik dan Ilmu Komputer, Universitas Komputer Indonesia, Indonesia ${ }^{2}$
}

\begin{abstract}
The purpose of this research is to determine the positive impact of the internet or e-commerce web for doll craft products marketing. Previously, the doll craft products have been marketed in a limited scope, as for now, the marketing is not only from someone's talk, or those who already know there will be a doll company but also for those who purchased and talks about the doll products to their friends or family. The research method used in this research is descriptive qualitative, which explains the overall picture of developing problems and creative ideas that will be innovative solutions. The result of this research is we better use renewable technology resources because as time goes on technology will become more renewable, as some people said "technology keeps away that is close and bring the distance closer." Technology makes us better in communicating with each other. The possibility, the feasibility, and other advantages are helping people to bring their product into the world. The impact of using e-commerce is it could increase the revenue of the company and reduce the cost.
\end{abstract}

Keywords: E-Commerce Benefits, Marketing

\section{Introduction}

E-commerce is one of the technologies that help us to distribute the product in the Cloud without any restrictions and boundaries [1]. The transaction could be done everywhere, processed in a minute, and easy to order. Trust is an important word in the e-commerce transaction, without any limitation about time, place, and countries. The development of information technology nowadays is a requirement that must be owned by every person or organization. It will help the technology to improve service quality. The implementation of the information systems must accompany the use of these technologies. Information technology and information systems are two fields that side by side in the delivery of organization information. Its use in an organization can help the need to maximize its goals. This is evidenced by the growing and easy role of information technology in the organization. Concerning in UMKM (small industry) is a productive business of an individual or an individual business entity that fulfills a micro business as stipulated in the law [2]. For the perception of the utilization of information technology as it should be, sometimes, the businessman or businesswoman is still experiencing problems, because it has not completely replaced the traditional way of making transactions. In digital market operations, the quality of design mechanisms and market trust are critical considerations in the public valuation of their value [3]. Trust has an important influence on consumers' activity and e-commerce success [4]. This was specifically developed to test the acceptance management software in the organizational settings. Therefore, most studies on acceptance of online shopping are considered especially the functional attributes of the Internet as a sales system (for example, 
perceived 'usability,' 'ease of use' or 'compatibility'). The effect of web vendor intervention on consumer behavior is assumed to be partly mediated by consumers' confidence [5].

It is important to transform this data into useful business analytics, which allows a better understanding to identify the strengths and weaknesses of e-commerce - the types of values generated for the user and the overall generation mechanism [4]. The strategies of the promotion are planning, implementation, and communication control of an organization to consumers and targets [6]. Companies make large investments in e-commerce applications, but it is very difficult to evaluate the success of their e-commerce systems. Sometimes online sellers are wrong and not serious. People are afraid to give their credit card and information online [6]. Customers may be skeptical to do shopping on an unknown e-commerce website that does not provide safety [2]. That is why a good number of online customers are available only on the most popular platforms, which have large-scale investments to protect customers' privacy and secure their purchases [7]. Despite the reduction of information asymmetry between sellers and buyers, there is interest in understanding the basis of customer loyalty in an online environment [3].

The purpose of this research was to determine the positive impact of the internet or ecommerce web for marketing doll craft products. The research method used in this research was descriptive qualitative, which explains the overall picture of developing problems and creative ideas that will be innovative solutions [7]. The results are comparison e-commerce with each other and contribute some qualitative description of using e-commerce and benefit. The impact of using e-commerce is it could increase the revenue of the company and reduce the cost [3]. The other impact is we could sell and give service for every product that every time without any restriction and boundary of the area [2].

\section{Material and Methods}

The research method used in this experiment is descriptive qualitative, which provides a comprehensive picture of a problem that develops with a creative idea that will be an innovative solution through an innovative policy. Descriptive qualitative is one of the statistical methods that explain phenomena based on review and some knowledge as an induction method to reach some answer. The method is consisted of survey, analysis, and find the answer about phenomena. The survey is one action direct to consumers and provides some questionnaires to ask some important questions about e-commerce and its use. The analysis is an activity to measure some questions and correlations within phenomena. Is there any significant answer that correlated with phenomena, we should to explain and give some reason why this occurred? The last step, we have to conclude the result from the descriptive-analytic and give some statement that related to the works.

\section{Results and Discussion}

To attract consumers in making some transactions on doll craft products, the seller should advertise on some free web e-commerce, then describe the details of what materials are used in making these dolls such as eye material, fabric material and the sewing process itself [9]. After that, the seller should clarify the advantages that can be obtained from buying the craft. For the payment, paying in several ways such as paying through transfer, or pay at a place through cash on delivery so that the seller and the buyer feel satisfied when making a direct transaction [10]. In addition, to minimize dissatisfaction from these buyers and to minimize fraud such as not sending money or making fake receipts from money transfers that are edited using the photo editing application for the seller, e-commerce is providing these features. In this case, the seller could make the time more efficient in selling or marketing their products through e-commerce information technology. Previously, sellers only waited for buyers who came to the store for a long time; it carries on because of the marketing of products through word of mouth or in the traditional way or by accidentally passing to the center of the doll craft [10]. On e-commerce marketing through the internet, all product details have been published so buyers that already know will come and immediately buy if the product matches up with what they want [7]. This discussion proposes one of the free e-commerce marketing websites for advertising, but for free 
the products that the marketers or advertisers have are the duration. If the seller wants to get other features then the seller must provide for long-term marketing and include a highlight feature. So that buyers who access the web look directly without searching first [8].

Fig. 1 shows a login or register menu. In this menu, the seller should register to create an account in order to market their product, or they could log in using their account if they already have an account on the existing social media.

\section{amazon}

\section{Create account}

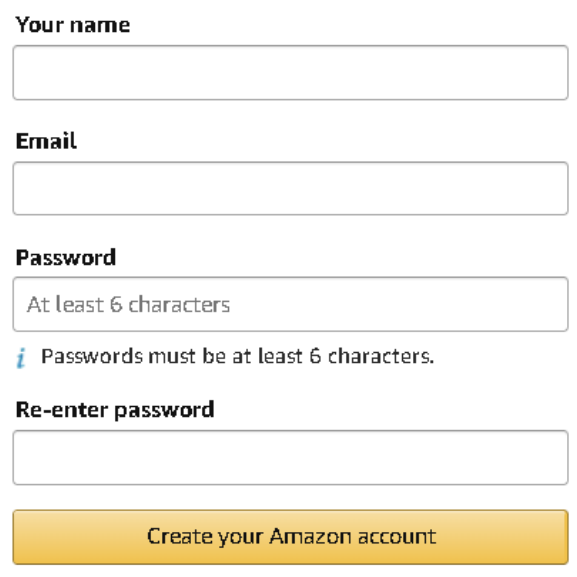

By creating an account, you agree to Amazon's Conditions of Use and Privacy Notice.

Fig 1. Login / Register Menu. The Figure was adapted from www.amazon.com, was taken on Oct 30, 2018.

Fig. 2 shows the main menu of the e-commerce website. Buyers will easily find the product they wanted on this menu. There are several menus and submenus. Buyers who have registered their accounts could search for the product that they want, as sellers could create some product advertisements to be marketed. 

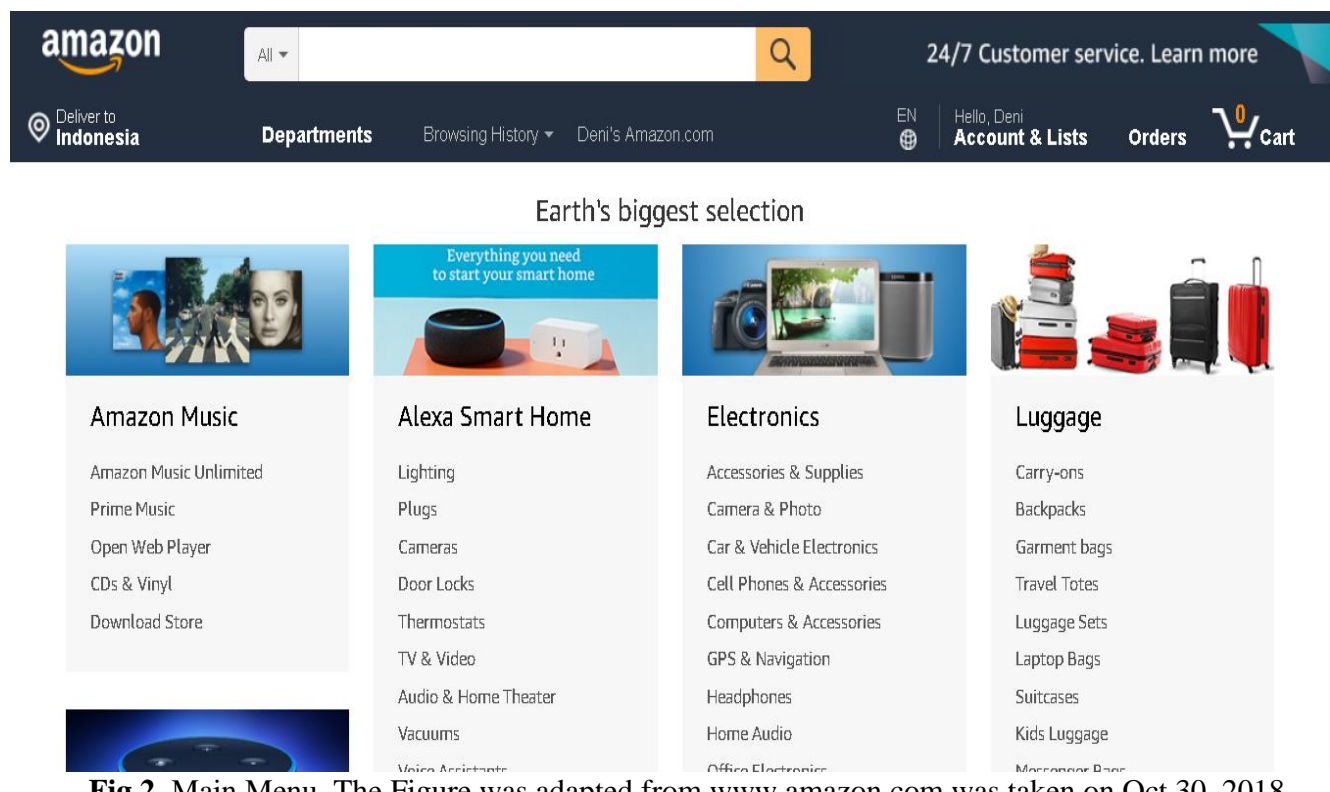

Fig 2. Main Menu. The Figure was adapted from www.amazon.com was taken on Oct 30, 2018.

Fig. 3 shows the display of a product when the buyer gets an attractive product, then it proceeds to see detailed images of the product, and the detail of making the doll.

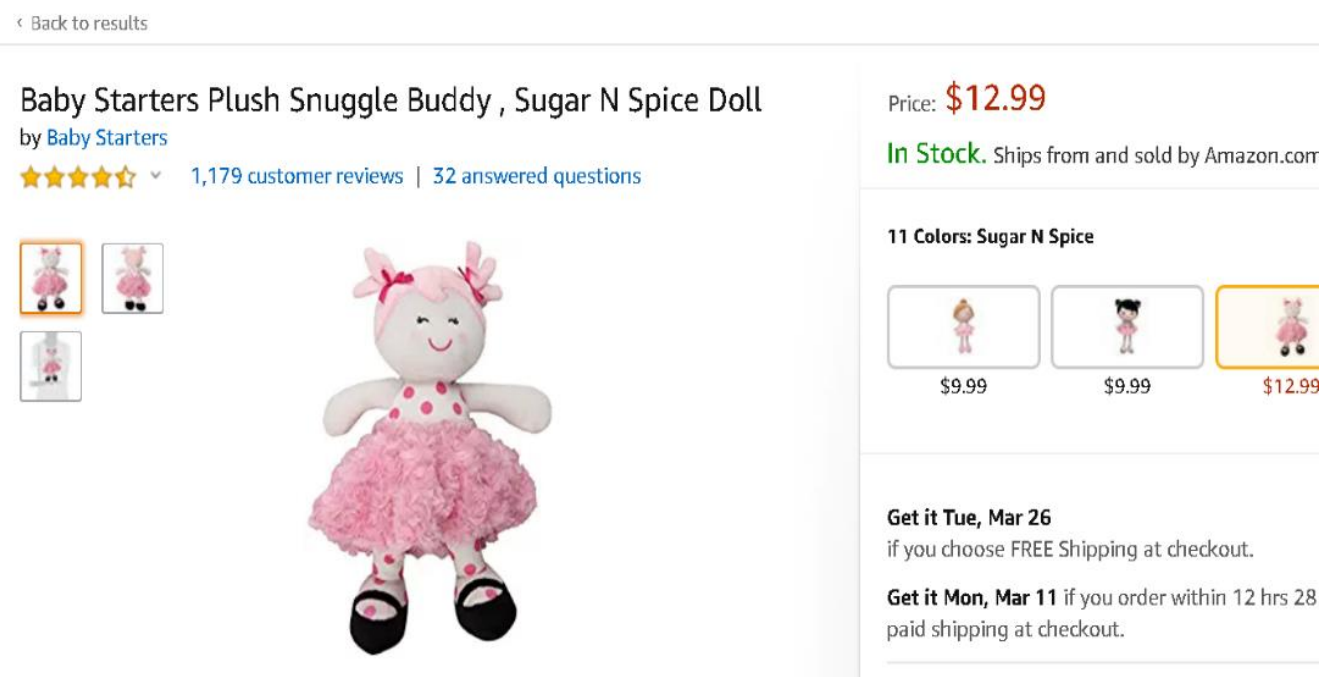

Fig 3. Product Menu amazon.com. The Figure was adapted from www.amazon.com was taken on Oct 30, 2018

Product details view shown in Fig.5. It explains the product material, how to order, how to make the product and the method of payment or shipping after the buyers deal to make a purchase (Fig. 4). 


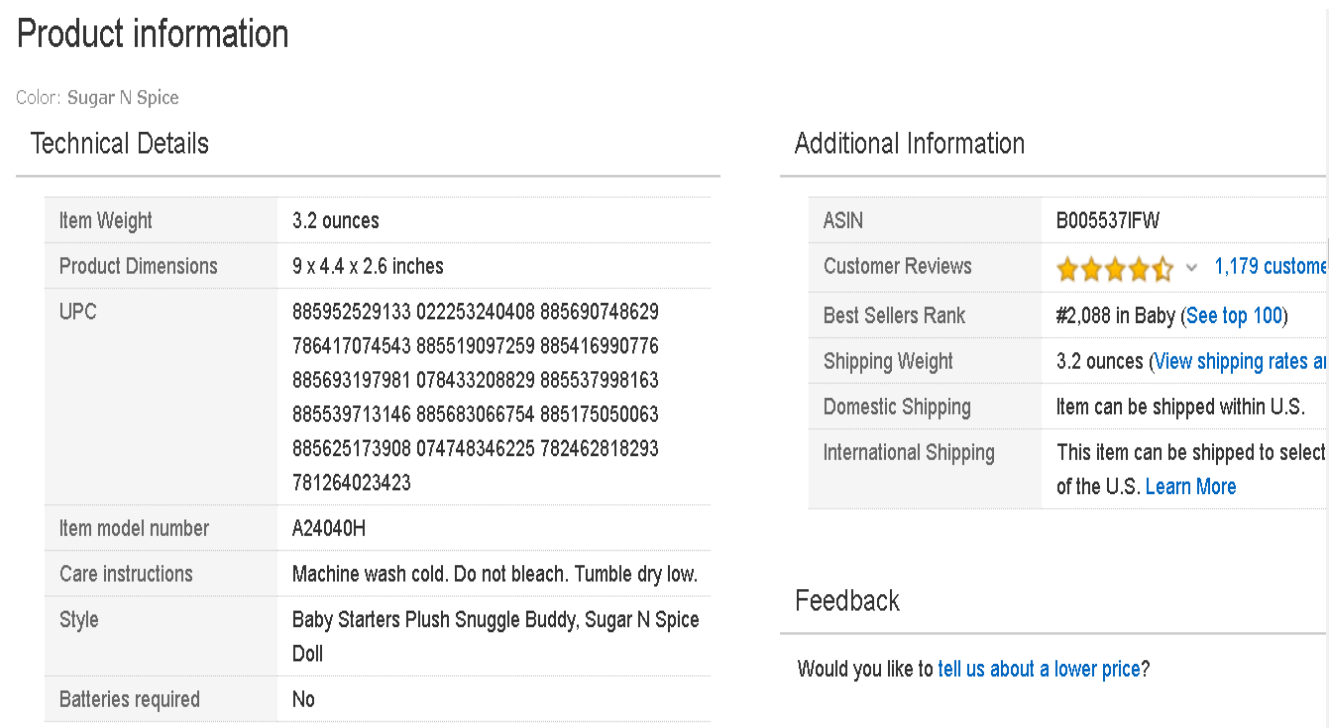

Fig 4. Product detail. The Figure was adapted from www.amazon.com was taken on Oct 30, 2018.

Fig. 5 shows the e-commerce web payment details. There will be a choice to pay on the spot if the seller and buyer in the same city, or transfer via ATM, then the seller will send the item via an expedition courier. After everything is finished there will be further notification if the shipment has been done, and the buyers have to wait for the item to arrive at their address [8].

\section{amazon.COM $\frac{\dddot{y}}{\text { SIGNIN SHIPPING \& PAYMENT GIFT OPTIONS PLACE ORDER }}$}

\section{Select a shipping address}

\section{Enter a new shipping address.}

When finished, click the "Continue" button.

Full name:

Address line 1:

Street address, P.O. box, company name, c/o

Address line 2:

Apartment, suite, unit, building, floor, etc.

Fig 5. Payment. The Figure was adapted from www.amazon.com. was taken on Oct 30, 2018. 


\section{Conclusion}

The development makes things easier for some people, especially in the business world such as organizations or individuals they call themselves actors in UMKM or small and micro-medium business language to do marketing at a limited cost. They can enjoy the sophistication of the internet, such as promoting or marketing their products for free and streamline their time in marketing their products, as well as their buyers. They also do not have to look for or visiting the area that produces the products, only through the internet e-commerce web they can immediately search and will not wait for a long time to get the product they wanted. As for payment transactions after making a purchase the buyer who does not want to make a direct purchase can send the money via ATM to the seller's account.

\section{References}

[1] K. Das and A. Ara.: Growth of E-Commerce in Nigeria. Int. J. Core Eng. Manag. 24 25-33. 2015.

[2] E. Soegoto and M. Rafi.: Internet role in improving business transaction. IOP Conference Series. Materials Science and Engineering, 407. 2018.

[3] M. Kim, N. Chung, and C. Lee. :The effect of perceived trust on electronic Commerce : Shopping online for tourism products and services in South Korea. Tour. Manag. 322 256-65. 2011.

[4] J. J. Wu, Y. H. Chen, and Y. S. Chung. :Trust factors influencing virtual community members: A study of transaction communities. J. Bus. Res. 63 9-10 1025-32. 2010.

[5] N. Hajli, J. Sims, A. H. Zadeh, and M. O. Richard.: A social commerce investigation of the role of trust in a social networking site on purchase intentions," J. Bus. Res. 71 133-41. 2017.

[6] S. M. Sheikh and M. Basti. :Customer Satisfaction in Business to Consumer ( B2C ) E-commerce : A Comparative Study of Turkey and Pakistan. Eur. J.of Bus. Eco. 8 16 73-100. 2015.

[7] D. Schöder, F. Ding, and J. K. Campos. :The Impact of E-Commerce Development on Urban Logistics Sustainability. Open J. Soc. Sci. 0403 1-6. 2016.

[8] Y. Hwang.: Computers in Human Behavior The moderating effects of gender on e-commerce systems adoption factors : An empirical investigation. Comput. Human Behav. 266 1753-60, 2010.

[9] M. Kadłubek. :The Selected Areas of E-logistics in Polish E-commerce," Procedia Comput. Sci. 65 1059-65. 2015.

[10] Y. Lu, L. Zhao, and B. Wang.: From virtual community members to C2C e-commerce buyers: Trust in virtual communities and its effect on consumers' purchase intention," Electron. Commer. Res. Appl. 94 346-60. 2010. 